\title{
Learning and Playing in Early Childhood with Augmented Reality Technology
}

Belajar dan Bermain pada Anak Usia Dini dengan Teknologi Augmented Reality

\section{Doni El Rezen Purba', Parasian D. P Silitonga ${ }^{2}$}

${ }^{1,2}$ Teknik Informatika, Universitas Katolik Santo Thomas Medan, Indonesia

1*donielrezenpurba@gmail.com, ${ }^{2}$ parasianirene@gmail.com

*: Penulis korenspondensi (corresponding author)

\section{Informasi Artikel}

Received: July 2021

Revised: August 2021

Accepted: September 2021

Published: October 2021

Keywords: Augmented Reality; Childhood Learning and Playing ; Game Education;

Kata kunci: Augmented Reality; Bermain dan Belajar Anak; Permainan Edukasi;

\begin{abstract}
Purpose: Helping the learning process in early childhood through playing and learning activities with Augmented Reality technology.

Design/methodology/approach: Using Augmented Reality technology with the Iterative Rapid Paper Prototype system development method

Findings/result: Based on tests conducted on 5 types of android devices, 10 samples of early childhood participants (4-5 years) and 5 groups of objects consisting of 10 types resulted in an increase in learning ability of $33.35 \%$ which was sourced from the measurement of the correct answers that were successfully obtained. between learning methods through pictures and learning using Augmented Reality technology

Originality/value/state of the art: In previous research, the learning model was carried out on elementary school children (aged 6 years and over) and without the implementation of Augmented Reality technology
\end{abstract}

Abstrak
Tujuan: Membantu proses belajar pada anak usia dini
melalui kegiatan bermain dan belajar dengan teknologi
Augmented Reality.
Perancangan/metode/pendekatan: Menggunakan teknologi
Augmented Reality dengan metode pengembangan sistem
Iterative Rapid Paper Prototype.
Hasil: Berdasarkan pengujian yang dilakukan terhadap 5
jenis perangkat android, 10 sampel peserta anak usia dini (4-
5 tahun) dan 5 kelompok objek benda yang masing terdiri
dari 10 jenis dihasilkan peningkatan kemampuan belajar
sebesar $33.35 \%$ yang bersumber dari pengukuran hasil
jawaban benar yang berhasil diperoleh antar metode belajar


melalui gambar dengan belajar menggunakan teknologi Augmented Reality.

Keaslian/ state of the art: Pada penelitian sebelumnya model pembelajaran dilakukan terhadap anak sekolah dasar ( usia 6 tahun keatas) dan tanpa implementasi teknologi Augmented Reality.

\section{Pendahuluan}

Dunia anak anak adalah dunia bermain, hampir seluruh aktivitas dihabiskan dengan bermain[1]. Aktifitas bermain anak-anak merupakan kegiatan yang dilakukan secara spontan. Bermain dilakukan oleh anak guna menjelajahi dunianya, mengembangkan kompetensi dalam usaha mengatasi lingkungan dan mengembangkan kreativitasnya[2]. Pembentukan dan perkembangan karakter anak juga dapat diciptakan melalui bermain[3]. Bermain merupakan cara alami anak untuk meningkatkan dan mengembangkan keterampilan, khususnya bagi anak usia dini. Karena ketika anak bermain mereka menggunakan banyak indera untuk menerima dan memperoleh beragam informasi dan meningkatkan pengetahuan mereka serta belajar mengenai jati dirinya[4]. Ketika bermain anak memiliki keterampilan dalam memahami suatu konsep dalam kehidupan secara alamiah tanpa adanya paksaan, sebab merupakan bentuk dari rasa keingintahuan yang tinggi namun mudah bosan[5]. Sehingga, dalam melaksanakan pembelajaran untuk anak usia dini harus lebih bervariatif[6][7]. Media yang dapat digunakan untuk pembelajaran selain dari buku adalah video permainan. Dengan bermain video permainan anak-anak mendapatkan media pembelajaran dan bermain yang menyenangkan[8]

Permainan edukasi merupakan bentuk permainan yang dirancang guna merangsang daya pikir dan kreativitas anak termasuk meningkatkan konsentrasi dan strategi penyeleaian masalah[9]. Bentuk pembelajaran interaktif yang efektif bagi anak usia dini adalah dengan bentuk implementasi Game edukasi, hal ini disebabkan rasa ingin tahu yang tinggi terhadap semua yang berada di lingkungan sekitarnya[10]. Permainan game edukasi berbentuk digital mengajarkan tentang permainan topik tertentu, guna memperluas konsep, memperkuat pembangunan, memahami sebuah peristiwa, sejarah atau budaya, atau membantu dalam belajar keterampilan ketika bermain[11]. Melalui permainan edukasi digital sebagai bentuk kegiatan pedagogis yang memungkinkan anak berinteraksi dan memahami dunia mereka melalui lingkungan digital[12]. Permainan jenis ini dapat digunakan sebagai penerapan pengetahuan faktual dan memperoleh pengalaman virtual, sehingga mampu membentuk perilaku, memori, refleksi dan pemahaman karena hasil kombinasi antara berlajar dan bermain[13]. Permainan Edukasi Digital dapat digunakan sebagai alat yang efektif dalam pembelajaran karena menciptakan motivasi dan kepuasan pribadi, mengakomodasi berbagai macam gaya dan keterampilan belajar, memberikan konteks interaktif dalam memecahkan masalah dan mengedepankan tindakan nyata dari pada hanya penjelasan[14].

Game digital memiliki berbagai jenis diantaranya, action, arcade, racing, fighting, shooting, action adventure, RTS, RPG, dan simulation. Augmented Reality merupakan perkembangan media pembelajaran yang saat ini tergolong masih baru. Beberapa perusahaan game terkemuka memanfaatkan teknologi augmented reality (AR) dalam membuat game. Augmented reality 
menggabungkan dunia nyata dan dunia digital dimana user dapat berinteraksi dengan dunia digital secara bersamaan dengan dunia nyata[15]. Dengan $A R$ dunia nyata dengan dunia maya digabungkan dalam bentuk dua dimensi maupun tiga dimensi yang diproyeksikan dalam sebuah lingkungan nyata dalam waktu yang bersamaan. Augmented Reality dapat digunakan dalam hiburan, kedokteran, mekanik, dan media pembelajaran. Augmented Reality dapat dibangun dengan menggunakan bantuan software Vuforia dan Unity 3D. Hasil akhir berupa media pembelajaran interaktif dengan Augmented Reality[16]. Teknologi augmented reality digunakan agar game lebih menarik untuk anak-anak dan diharapkan menarik minat dari anak untuk belajar[8]. Kombinasi antara transformasi teknologi augmented reality (AR) dengan mobile game mampu menerobos industri pendidikan dengan mengembangkan pembelajaran simulasi dan game edukasi[17][18].

\section{Metode/Perancangan}

Metode yang digunakan adalah dengan model Iterative Rapid Paper Prototype. Dipilih karena kemudahannya untuk membuat sebuah cetak biru dari game yang akan dibangun, walaupun game yang akan dibangun adalah sebuah game digital. Tidak dibutuhkan perlengkapan yang rumit, paper prototype dapat dibuat dengan peralatan apapun seperti, pensil atau spidol, kertas karton, atau kertas ukuran A4. Gambar 1 merupakan model Iterative Rapid Paper Prototype.

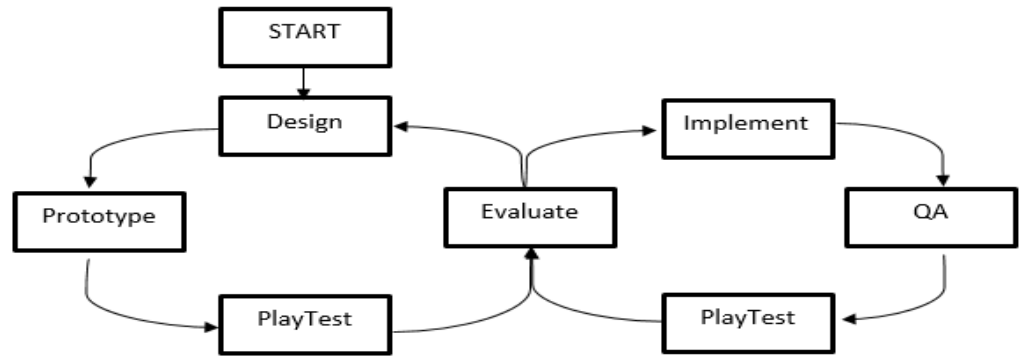

Gambar 1. Iterative Rapid Paper Prototyping

Melalui paper prototype diperoleh keuntungan kecepatan dalam merancang prototype dari game dan pengimplementasian rancangan dengan mudah[19]. Iterasi pada paper prototyping dilakukan dengan mendesain permainan yang akan dirancang kedalam desain permainan edukasi yang belum digital dan dicoba berulang kali untuk menguji rule yang sudah diimplementasikan ke dalam game yang telah dirancang. Kekurangan dari peraturan yang diimplementasikan akan terlihat pada setiap iterasi yang sudah dilakukan. Keunggulan yang diperoleh dari iterative paper prototype, semakin sering dilakukannya iterasi dan semakin sering melewati tahap-tahap perancangan dan implementasi game akan menjadi lebih baik.

\subsection{Rancangan Sistem}

Arsitektur sistem terlihat seperti pada Gambar 2, pemain menggunakan telepon pintar android dan mengarahkan kamera terhadap marker yang telah ditentukan sebelumnya. 

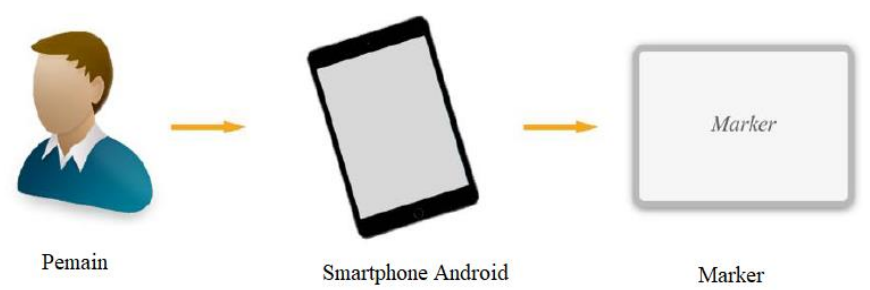

Gambar 2. Arsitektur sistem

Case diagram untuk permainan ini terlihat seperti Gambar 3, pemain dapat memilih menu untuk memulai AR, melihat panduan, soal latihan dan keluar untuk menutup aplikasi.

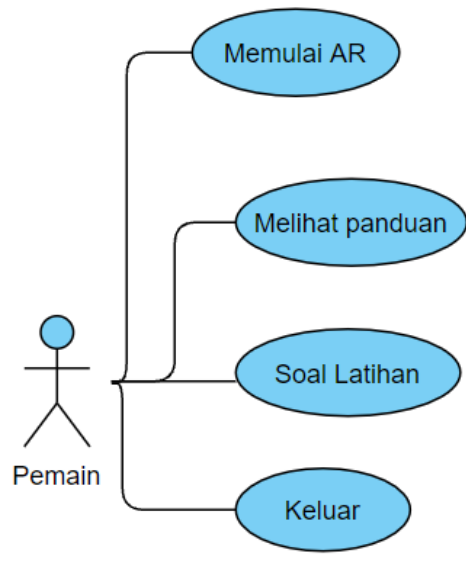

Gambar 3. Case Diagram

\subsection{Proses Augmented Reality}

Augmented Reality (AR) bekerja berdasarkan deteksi citra (gambar), citra yang digunakan merupakam marker yang telah ditentukan. Prinsip kerjanya adalah kamera yang telah dikalibrasi akan mendeteksi marker yang diberikan, kemudian setelah dikenali pola dari marker, kamera akan melakukan pencocokan apakah marker sesuai dengan data yang dimiliki dalam basisdata atau tidak. Jika tidak sesuai, maka informasi marker tidak akan diproses, namun bila sesuai maka informasi marker yang telah ditangkap melalui kamera akan digunakan untuk me-render dan menampilkan objek 3 dimensi atau animasi yang telah ditentukan sebelumnya. Gambar 4 menunjukkan proses kerja $A R[20]$. 


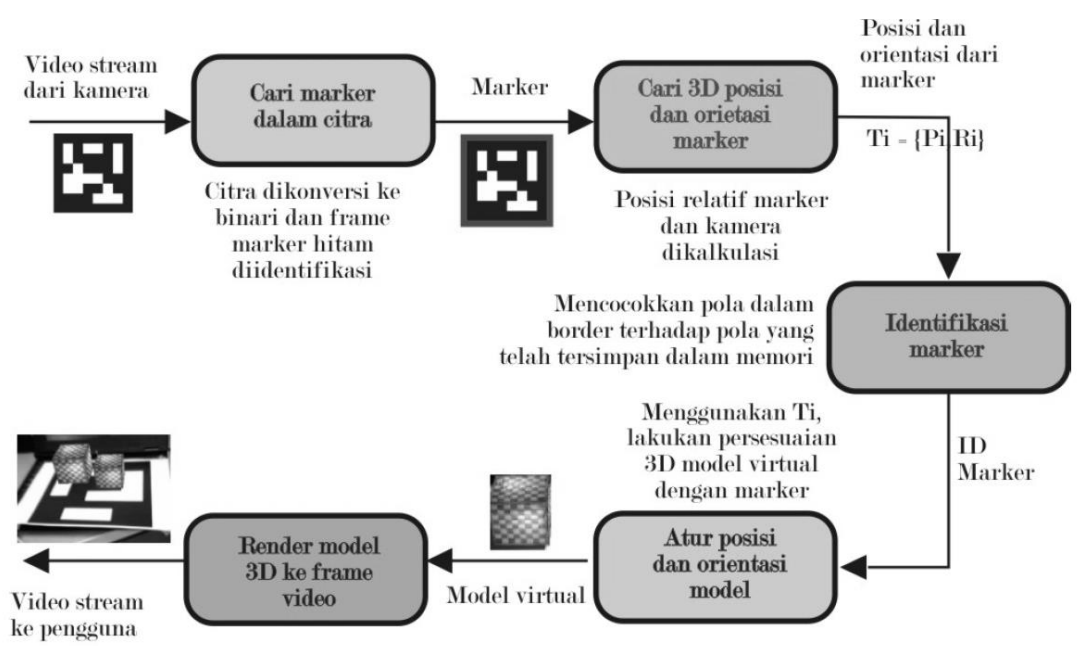

Gambar 4. Proses Kerja $A R$

(Yuri Yudhaswana Joefrie dan Yusuf Anshori, 2011)

\section{Hasil dan Pembahasan}

\subsection{Antar Muka Aplikasi}

Antarmuka perangkat lunak dikembangkan dengan menggunakan beberapa pustaka. Beberapa diantaranya adalah :

- Unity sebagai membangun aplikasi android;

- Vuforia SDK sebagai kakas bantu Augmented Reality;

- Blender sebagai pembangun objek tiga dimensi;

- Androidsdk sebagai kakas bantu untuk develompent android;

Halaman utama aplikasi permainan edukasi dengan Augmented Reality yang telah selesai di kembangkan terlihat seperti pada Gambar 5 berikut.

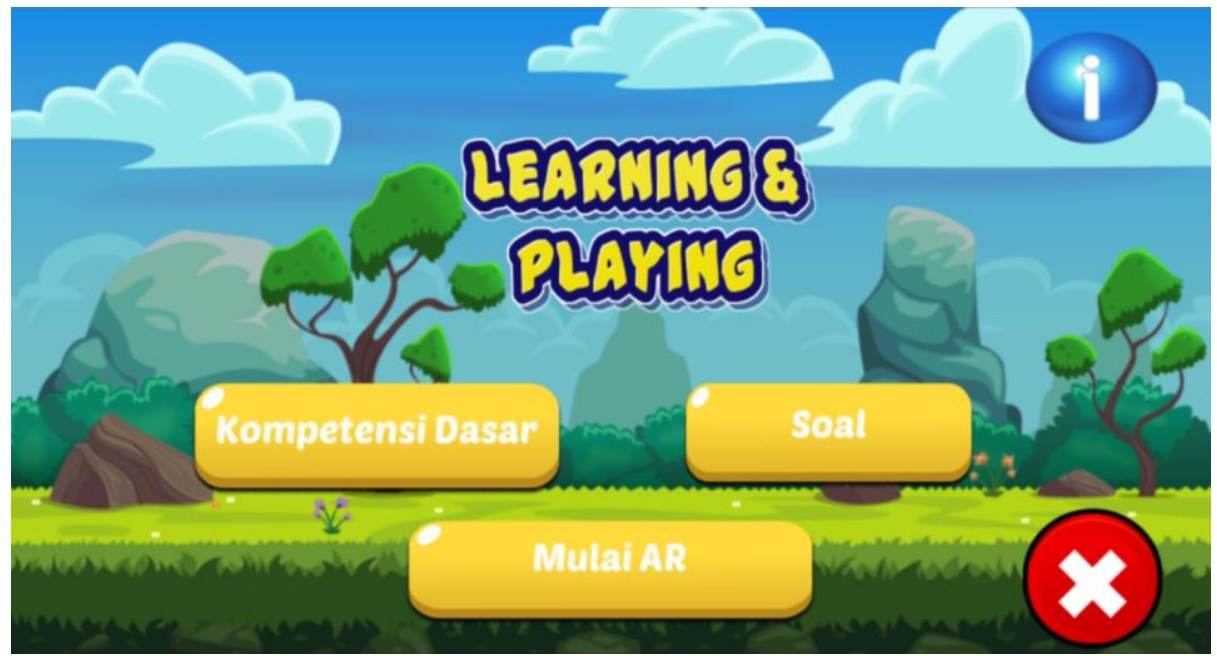

Gambar 5. Halaman Utama Aplikasi

Proses pembelajaran dengan menggunakan video kamera Augmented Reality disajikan seperti pada Gambar 6. Ketika menu Mulai AR dipilih kamera akan aktif dan saat kamera menemukan marker 
yang sesuai dengan yang terdapat pada basisdata maka objek 3 dimensi akan tampil bersamaan dengan suara hewan serta penjelasannya.
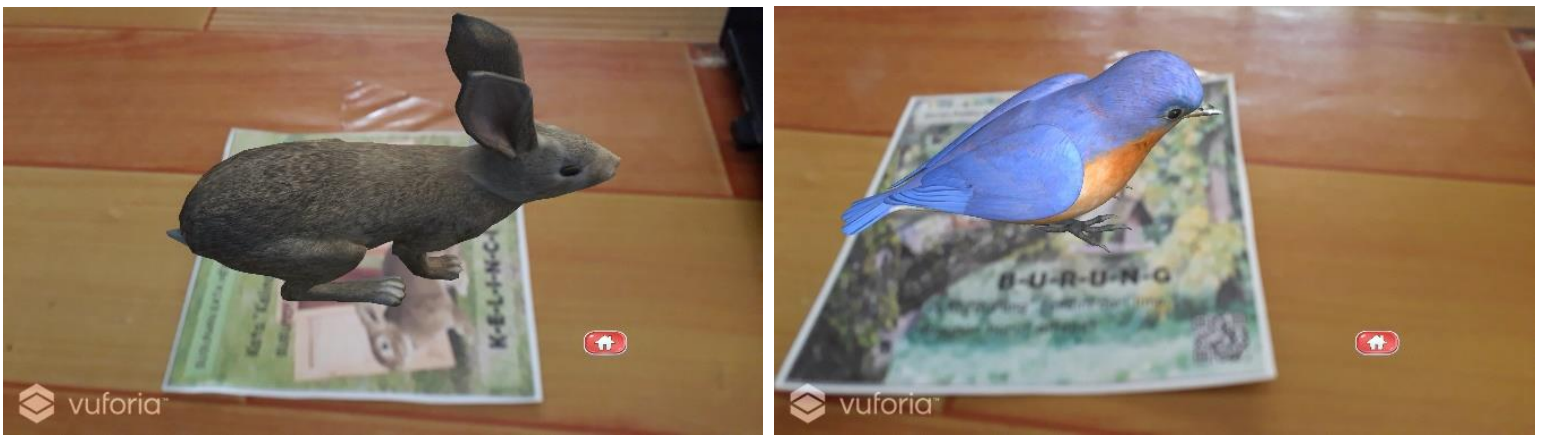

Gambar 6. Kamera AR menyajikan objek 3 dimensi

Setelah selesai proses pembelajaran melalui video Augmented Reality pemain game edukasi dapat melanjutkan dengan mengerjakan soal-soal latihan untuk menguji seberapa jauh pemahaman mereka. Penilaian akan dilakukan berdasarkan jawaban benar yang berhasil diselesaikan. Setiap jawaban benar akan diberi nilai. Proses pengerjaan soal latihan disajikan seperti pada Gambar 7.
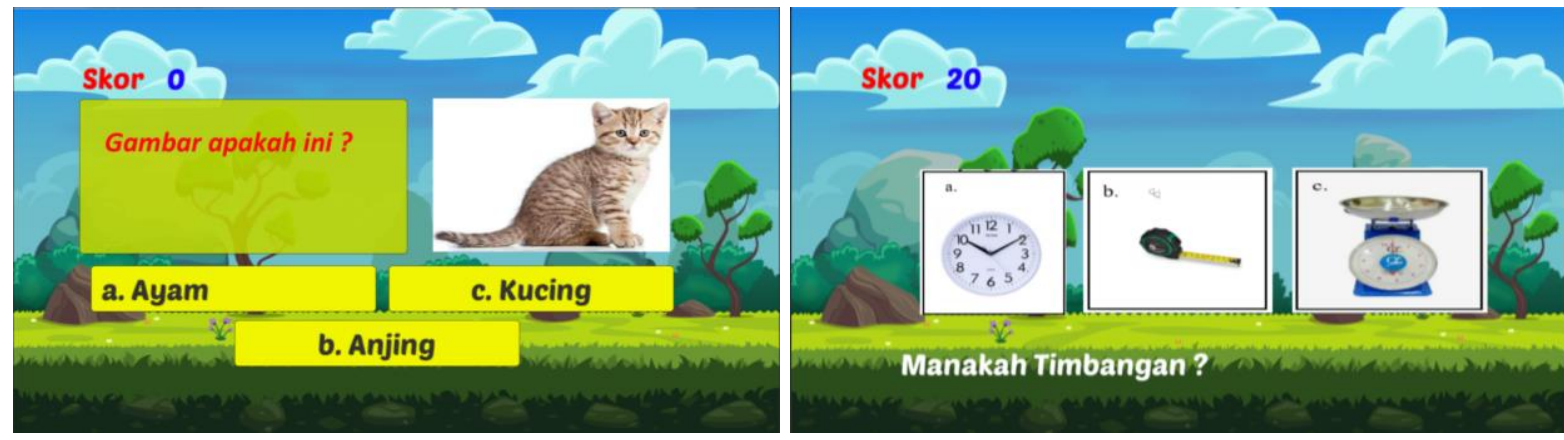

Gambar 7. Soal Latihan

\subsection{Hasil Pengujian}

\subsubsection{Pengujian Alpha}

Pengujian alpha meliputi dari proses menampilkan tiap halaman, suara dan hasil objek 3 dimensi yang dihasilkan pada beberapa merk perangkat android, setelah lolos dari pengujian alpha selanjutnya akan dilakukan pengujian beta oleh target pemain. Tabel 1 merupakan hasil dari pengujian Alpha.

Tabel 1. Hasil Pengujian Alpha

\begin{tabular}{llccc} 
No. & Merk Pergangkat & \multicolumn{3}{c}{ Hasil (Baik, Kurang Baik, Gagal) } \\
\hline & & Tampilan & Suara & Objek 3 Dimensi \\
\hline 1. & Samsung J3 Prime & Baik & Baik & Baik \\
\hline 2. & Vivo y12 & Kurang & Baik & Baik \\
\hline 3. & Xiaomi Redmi 9A & Baik & Baik & Baik \\
\hline 4. & Oppo A3S & Baik & Baik & Kurang \\
\hline 5. & Asuz zenfone 2 & Baik & Baik & Kurang \\
\hline
\end{tabular}




\subsubsection{Pengujian Beta}

Pengujian beta adalah proses pengujian yang dilakukan langsung kepada pengguna, yaitu anak usia dini. Pengujian dilakukan dengan cara bermain dan belajar dengan alat bantu gambar dan dengan cara memainkan aplikasi permainan edukasi $A R$ terhadap 5 kelompok objek yang masing-masing terdiri dari 10 jenis. Pengambilan sampel diberikan kepada 10 anak usia dini yang berumur 4 - 5 tahun. Pada Tabel 2 dan Gambar 8 disajikan hasil pengujian belajar dan bermain dengan gambar dan dengan permainan AR terhadap jawaban benar yang berhasil diperoleh.

Tabel 1. Pengujian bermain dengan Gambar dan Beramin dengan Augmented Reality

\begin{tabular}{clcc} 
No & Kelompok Objek & Dengan Gambar & Dengan AR \\
\hline 1 & Hewan & 7 & 9 \\
\hline 2 & Buah & 6 & 8 \\
\hline 3 & Sayuran & 5 & 7 \\
\hline 4 & Alat Ukur & 4 & 5 \\
\hline 5 & transportasi & 5 & 7 \\
\hline 6 & Rata-rata & 5.4 & 7.2 \\
\hline
\end{tabular}

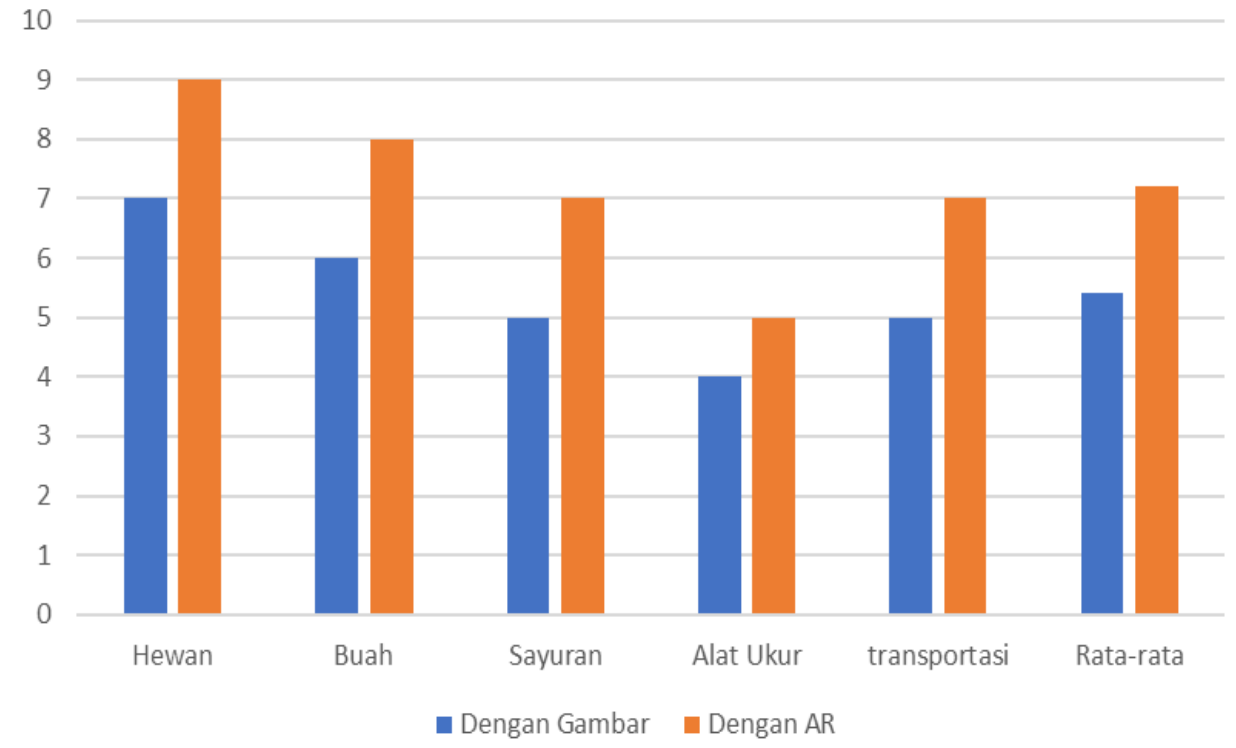

Gambar 7. Pegujian dengan Gambar dan dengan $A R$

\section{Kesimpulan dan Saran}

Melalui penelitian yang telah dilakukan dihasilkan kesimpulan bahwa teknologi Augmented Reality dapat berjalan dengan baik pada sampel beberapa perangkat android dengan spesifikasi minimul $1 \mathrm{~Gb}$ memory. Hasil pengujian yang dilakukan terhadap pemain juga diperoleh pengingkatan kemampuan belajar sebesar 33.35\% dari sampel 10 anak usia dini dengan 5 kelompok objek yang masing masing terdiri dari 10 jenis benda. Untuk penelitian selanjutnya dapat disarankan untuk melibatkan lebih banyak sampel pemain yang terdiri dari beberapa 
kelompok usia dan objek pembelajaran yang lebih bervariatif untuk memperoleh tingkat keakuratan hasil penelitian yang lebih baik.

\section{Daftar Pustaka}

[1] Z. Trinova, "Hakikat Belajar Dan Bermain Menyenangkan Bagi Peserta Didik," Al-Ta lim J., vol. 19, no. 3, pp. 209-215, 2012, doi: 10.15548/jt.v19i3.55.

[2] K. Z. Putro, "Mengembangkan Kreativitas Anak Melalui Bermain," Apl. J. Apl. Ilmuilmu Agama, vol. 16, no. 1, p. 19, 2016, doi: 10.14421/aplikasia.v16i1.1170.

[3] A. Aprilianto and W. Mariana, "Permainan Edukasi (Game) Sebagai Strategi Pendidikan Karakter," Nazhruna J. Pendidik. Islam, vol. 1, no. 1, pp. 139-158, 2018, doi: 10.31538/nzh.v1i1.47.

[4] R. Lamrani, E. H. Abdelwahed, S. Chraibi, S. Qassimi, and M. Hafidi, Gamification and serious games based learning for early childhood in rural areas, vol. 929. Springer International Publishing, 2018.

[5] F. Wahyuni and S. M. Azizah, "Bermain dan Belajar pada Anak Usia Dini," Al-Adabiya J. Kebud. dan Keagamaan, vol. 15, no. 01, pp. 161-179, 2020, doi: 10.37680/adabiya.v15i01.257.

[6] A. S. Cahyaningtyas, "Pembelajaran Menggunakan Augment Reality Untuk Anak Usia Dini Di Indonesia," J. Teknol. Pendidik. J. Penelit. dan Pengemb. Pembelajaran, vol. 5, no. 1, p. 20, 2020, doi: 10.33394/jtp.v5i1.2850.

[7] M. Maulidina, S. Susilaningsih, and Z. Abidin, "Pengembangan Game Based Learning Berbasis Pendekatan Saintifik Pada Siswa Kelas Iv Sekolah Dasar," JINOTEP (Jurnal Inov. dan Teknol. Pembelajaran) Kaji. dan Ris. dalam Teknol. Pembelajaran, vol. 4, no. 2, pp. 113-118, 2018, doi: 10.17977/um031v4i22018p113.

[8] B. N. Pelealu, T. Afirianto, and W. S. Wardhono, "Pengembangan Game Edukasi Mobile Augmented Reality untuk Membantu Pembelajaran Anak dalam Membaca, Menulis, dan Berhitung," J. Pengemb. Teknol. Inf. dan Ilmu Komput., vol. 3, no. 2, pp. 1492-1499, 2019.

[9] S. Isabell Maleva, "Permainan Edukatif dalam Mengembangkan Kreativitas Anak Usia Dini Di Kelompok Bermain Jami'atul Quro' Kota Magelang," J. Pendidik. dan Kebud., vol. 9, no. 2, pp. 95-106, 2017.

[10] R. A. Rahman and D. Tresnawati, "Pengembangan Game Edukasi Pengenalan Nama Hewan dan Habitatnya Dalam 3 Bahasa Sebagai Media Pembelajaran Berbasis Multimedia," J. Algoritm., vol. 13, no. 1, pp. 184-190, 2016, doi: 10.33364/algoritma/v.13-1.184.

[11] A. V. Vitianingsih, "Game Edukasi Sebagai Media Pembelajaran PAUD," J. Inf., vol. 1, no. 1, pp. 1-8, 2016.

[12] S. Edwards, "Digital play in the early years: A contextual response to the problem of integrating technologies and play-based pedagogies in the early childhood curriculum," Eur. Early Child. Educ. Res. J., vol. 21, no. 2, pp. 199-212, 2013, doi: 
10.1080/1350293X.2013.789190.

[13] Z. Nikiforidou, "Digital Games in the Early Childhood Classroom: Theoretical and Practical Considerations," Int. Perspect. Early Child. Educ. Dev., vol. 22, pp. 253-265, 2018, doi: 10.1007/978-981-10-6484-5_16.

[14] M. Kebritchi and A. Hirumi, "Examining the pedagogical foundations of modern educational computer games," Comput. Educ., vol. 51, no. 4, pp. 1729-1743, 2008, doi: 10.1016/j.compedu.2008.05.004.

[15] "PERKEMBANGAN TEKNOLOGI AUGMENTED REALITY SEBAGAI MEDIA PEMBELAJARAN INTERAKTIF PADA MATA KULIAH KIMIA DASAR,” vol. IX, no. $1,2015$.

[16] L. Hakim, "Pengembangan Media Pembelajaran Pai Berbasis Augmented Reality," Lentera Pendidik. J. Ilmu Tarb. dan Kegur., vol. 21, no. 1, pp. 59-72, 2018, doi: 10.24252/lp.2018v21n1i6.

[17] P. Ary and E. S. Wibowo, "APLIKASI AUGMENTED REALITY GAME EDUKASI UNTUK PENGENALAN ORGAN TUBUH MANUSIA," Angew. Chemie Int. Ed. 6(11), 951-952., pp. 5-24, 1967.

[18] M. Faqih, A. Kusumaningsih, and A. Kurniawati, "Penerapan Augmented Reality Pada Serious Game Edukasi Penyakit Gigi," Simetris J. Tek. Mesin, Elektro dan Ilmu Komput., vol. 9, no. 2, pp. 1033-1042, 2018, doi: 10.24176/simet.v9i2.2536.

[19] J. Gibson, Introduction to Game Design, Prototyping, and Development: From Concept to Playable Game with Unity and C\#. 2014.

[20] Y. A. Yuri Yudhaswana Joefrie, "TEKNOLOGI AUGMENTED REALITY," JTT (Jurnal Teknol. Ter., vol. 1, no. 1, 2018, doi: 10.31884/jtt.v1i1.36. 